\title{
PROPUESTAS Y OPINIONES EN TORNO DE UN PRINCIPIO DE OPORTUNIDAD PARA COLOMBIA
}

\author{
Daniel Medina García* \\ Sylvana Peña Saffon** \\ César Ramírez Salazar ${ }^{* * *}$
}

\begin{abstract}
Resumen. El principio de oportunidad es una institución importada de sistemas con tendencia acusatoria que se puede implementar en Colombia adecuándola a nuestra Constitución. En nuestro sistema procesal penal el principio de oportunidad se ha relegado al lugar de figura excepcional, sin embargo, la Constitución permite y requiere que este sea un mandato de optimización, por ello su regulación legal y reglamentaria debe estar conforme a este requerimiento constitucional y esto se logrará concibiendo de manera distinta
\end{abstract}

* Abogado de la Universidad Externado de Colombia, especialista en ciencias penales y criminológicas, candidato a magíster en Ciencias Penales y Criminológicas y estudiante de la Especialización en Derecho Procesal Penal de la misma Universidad. Bogotá D.C., Colombia. Correo-e: drdanielmedina@gmail.com.

** Abogada de la Universidad de los Andes y estudiante de la Especialización en Derecho Procesal Penal de la Universidad Externado de Colombia. Bogotá D.C., Colombia. Correo-e: sylvanasaffon@ gmail.com.

*** Abogado de la Universidad Javeriana y estudiante de la Especialización en Derecho Procesal Penal de la Universidad Externado de Colombia. Bogotá D.C., Colombia. Correo-e: cesarsramirezsalazar@ gmail.com. Fecha de recepción: 21 de septiembre de 2016. Fecha de modificación: 15 de noviembre de 2016. Fecha de aceptación: 24 de febrero de 2017. Para citar el artículo: Daniel MEDINA García, Sylvana Peña Saffon, César Ramírez Salazar. "Propuestas y opiniones en torno de un principio de oportunidad para Colombia", en Revista Derecho Penal y Criminología, Vol. 37, n. ${ }^{\circ}$ 103, julio-diciembre de 2016, Bogotá: Universidad Externado de Colombia, pp. 109-143, DOI: https://doi.org/10.18601/01210483.v37n103.06 
esta figura, extendiéndola a otros supuestos de aplicación y haciendo más fluido el trámite de la misma.

Palabras clave: Principio de oportunidad, mandato de optimización, mecanismo sancionatorio alternativo, modelo de Estado, Constitución Política, Ley 906 de 2004, reglamentación interna de la Fiscalía General de la Nación, ampliación de ámbito de aplicación y fluidez en ejercicio de la discrecionalidad.

\section{PROPOSSALS AND OPINIONS AROUND PLEA BARGAINS IN COLOMBIA}

Summary. The principle of opportunity is an institution imported from the systems with accusatory trend. It can be implemented in Colombia if it is according to our Constitution. In our criminal justice system the opportunity has been relegated to the place of an exceptional figure, however, the Constitution requires that the opportunity can be a general rule, so the legal rules must be in accordance with this constitutional requirement, and It will be achieved if we envisage this figure of these way, apply to other cases and making its process more fluid.

Keywords: Principle of opportunity, mandate of optimization, alternative sanction mechanism , model of State, Constitution, Law 906 of 2004, internal regulations of the Attorney General's Office, expansion of scope and fluidity in exercise of opportunity.

\section{INTRODUCCIÓN}

El principio de legalidad se manifiesta en la obligación de investigar, acusar y juzgar las conductas punibles puestas en conocimiento de las autoridades penales para que el proceso penal cumpla sus finalidades esenciales, verbigracia garantizar el cumplimiento de la ley sustancial ${ }^{1}$. Por otra parte, el principio de oportunidad es una institución procesal que permite al Estado la renuncia, interrupción y suspensión de la persecución penal por los delitos puestos en su conocimiento. Este principio busca dar solución a un conflicto suscitado por un delito en el marco de un Estado social y democrático de derecho y sancionar y reprimir la criminalidad de una manera alternativa a la del principio de legalidad; sin embargo, ha sido regulado de una manera que lo vuelve un instrumento excepcional y lo hace confundir con la impunidad.

Esta es una visión sesgada del principio de oportunidad que sigue en la conciencia popular, a pesar de los más de diez años de la Ley 906, y se debe a que este principio no se ha comprendido como un mandato de optimización que requiere la más

1 Barbosa Castillo, Gerardo (2005). "Principio de legalidad y proceso penal”, en Revista Derecho Penal y Criminología, Vol. 26, n. ${ }^{\circ} 78$, enero-junio de 2005, Bogotá: Universidad Externado de Colombia, 2005, p. 117. 
abundante aplicación posible y se ha regulado de una forma que no facilita su fluida aplicación. Teniendo en cuenta este problema, el propósito de este escrito es exponer cómo concebimos los estudiantes de la Especialización de Procesal Penal 2016-2017 de esta casa de estudios el principio de oportunidad en Colombia.

Para este cometido pretendemos hacer unas breves pero útiles alusiones al principio de oportunidad en el derecho comparado para observar qué es útil y qué no de otros países, de acuerdo con los límites constitucionales y nuestra realidad jurídica; explicar cómo debe entenderse un principio de oportunidad conforme a nuestra Constitución y cómo ha sido su desarrollo normativo; para después hacer propuestas que hagan más fluida la aplicación de esta herramienta procesal y político-criminal.

\section{PRINCIPIO DE OPORTUNIDAD Y LA DISCRECIONALIDAD EN EL DERECHO COMPARADO}

La génesis del principio de oportunidad se encuentra en los sistemas de tendencia adversarial en los que se "atribuye la iniciativa a la parte ofendida" para acusar. Por ello, no resulta raro que "el poder de acusación haya sido discrecional" 2 , sin embargo, la necesidad de la intervención de organismos públicos en la administración de justicia y la persecución del delito ha permitido que el ofendido no sea el único que tenga la potestad de acusar y renunciar a su acusación, sino que esta sea también una potestad pública.

El sistema anglosajón tiene como característica "la existencia de atribuciones discrecionales en los organismos o personas encargadas de promover la acusación para dar inicio al proceso penal"3, mientras que los sistemas europeo continentales implementaron con posterioridad mecanismos que facilitaran la priorización en la investigación penal y en ocasiones de renuncia de la acción penal, siempre teniendo como principio prevalente el principio de legalidad, obligatoriedad y oficialidad de la acción penal.

Para entender el funcionamiento y los matices de la discrecionalidad en el ejercicio de la acción penal nos resulta conveniente una breve contextualización de la discrecionalidad en Inglaterra y Estados Unidos, como punto de referencia de los sistemas de corte anglosajón; de Italia, Alemania y España, como ejemplos icónicos del sistema continental; y de Chile, como muestra de aplicación del principio de oportunidad en américa latina.

2 Forero Ramírez, Juan Carlos (2013). Aproximación al Estudio del Principio de Oportunidad. Bogotá: Editorial Ibañez, p. 25.

3 Mestre Ordoñez, José Fernando (2011). La discrecionalidad para acusar. Bogotá: Editorial Ibañez, p. 166. 


\subsection{Sistema anglosajón}

Es una característica de los sistemas anglosajones la existencia de facultad discrecional para ejercer la acción penal ${ }^{4}$. Los dos países que han caracterizado este sistema han sido Inglaterra y Estados Unidos. Entre ambos existen diferencias en la manera como se aplica el principio de oportunidad y sobre quién debe ejercer la acción penal, pero no en cuanto al ejercicio de la discrecionalidad de la acción penal.

\section{i. Inglaterra}

En principio no existe una entidad del Estado encargada de la investigación y acusación penal que se asimile a la Fiscalía General de la Nación ${ }^{5}$ y, en consecuencia, no existe monopolio sobre el ejercicio de la acción penal pues, si bien el ejercicio de la acción penal es una función "descentralizada que corresponde a la policía" , cualquier persona está facultada para ejercerla a nombre de la Corona $^{7}$.

Existe una institución denominada Crown Prosecution Services (CPS) cuya principal función es la de asesorar a la policía o a quien va a ejercer la acción penal en relación con aspectos como determinar el delito por el cual se van a formular cargos o sobre qué casos deben ser investigados, entre otros ${ }^{8}$. El Director of Public Prosecutions (DPP) por su parte es quien se encuentra al mando de la CPS, y su labor se centra en dirigir y cumplir con las funciones otorgadas a este.

Dado el modelo elegido para ejercer la acción penal, esta se ejerce de manera discrecional, sin que existan causales taxativas de procedibilidad en la ley ni una obligación de acusar basada en el principio de legalidad de una forma tan encumbrada como en los países del sistema continental. Al no presentarse de una forma tan rigurosa el principio de oficiosidad de la acción penal, no es obligatorio el control de un juez a la facultad de renunciar a la persecución penal. Sin que esta ausencia de control ju-

4 Ibidem.

5 Ibidem.

6 Ibidem, p.167.

7 "In England, on the contrary, the prosecution of criminal offenses, save in those special classes of cases which are conducted through the agency of governmental officials such as the Law Officers of the Crown, the Director of Public Prosecutions or the solicitors to the government departments and boards, is in legal theory left wholly to the agency of private individuals who are not compelled to set the law in motion and who have only within comparatively recent years been encouraged to do so by legislative provisions authorizing the repayment on a still inadequate scale of the costs of the actions out of public fund". Consultar Fuente: Pendleton, Howard (Jun., 1929). "Criminal Prosecution in England. I. Police Prosecutions”, en Columbia Law Review, Vol. 29, n. 6, p. 716.

8 Disponible http://www.cps.gov.uk/victims_witnesses/reporting_a_crime/decision_to_charge.html Consultado el 01/08/2016. 
dicial a la discrecionalidad excluya la posibilidad de controlar la legalidad de dicha renuncia como a un acto administrativo discrecional a través de un trámite ajeno al proceso penal.

A pesar de la eventual inexistencia de un control judicial a la discrecionalidad de acusar en el proceso penal, existe un control político que se realiza a órganos como el CPS y el DPP ${ }^{9}$, pero no a los particulares cuando van a ejercer la acción Penal.

\section{ii. Estados Unidos}

A diferencia de Inglaterra, en Estados Unidos sí existen órganos estatales que ejercen la acción penal de manera monopólica ${ }^{10}$, dependiendo de la estructura del Estado (existen dos niveles: el Federal y Estatal). El ente acusador de Estados Unidos (el Federal y el Estatal) es de carácter político y cada una de las "fiscalías se inspira en la idea de legitimación democrática y responsabilidad política, bien porque quien la dirige es directamente elegido por el pueblo, bien porque es nombrado por el poder ejecutivo, que a su vez es electivo" 11 .

"En el sistema norteamericano, y en eso lo sigue Puerto Rico, a quien le corresponde la tarea de mantener el orden público, de velar por la integridad de los asociados, de adelantar las investigaciones y formular la acusación es al Ejecutivo"12. En ese sentido, cuando el fiscal considera que no es conveniente u oportuno acusar, puede no hacerlo.

Aunque suene arriesgado decirlo, consideramos que en el sistema de Estados Unidos el principio de oficiosidad o legalidad estricta no existe, ya que la acción penal depende de la discrecionalidad del ejecutivo y de las negociaciones Plea Bargaining, que se definen como "an explicit or implicit exchange of concessions by the parties. Usually, the acussed agrees to plead guilty and the goverment agrees to some form of reduction in charges or sentence" 13 , sin que la obligación de acusar y condenar los delitos conforme a las penas que prevé la ley sustancial sea la regla general, pues la procedencia de las negociaciones de culpabilidad y beneficios penales no tiene una

9 Ibidem.

10 Ibidem, p.168.

11 Diez-Picazo, Luis Marìa (2000). El poder de acusar. Ministerio fiscal y Constitucionalismo. Barcelona: Ariel Derecho, p. 75, en José Fernando Mestre OrdoñEZ (2011). La discrecionalidad para acusar. Bogotá: Editorial Ibañez, p. 168.

12 Granados PEÑA, JAIME (1996). El sistema acusatorio en el derecho comparado y la nueva fiscalía general en Colombia. Bogotá: Editorial Ibañez, pp. 33-35.

13 Colquitt, Joseph (feb., 2001). Ad hoc plea Bargaining. Tulane Law Review, n. 75 , en StePHEN A. Salzburg y Daniel J. CAPRA (2010). American criminal procedure. Estados Unidos: West, p. 1030. 
camisa de fuerza que restrinja las posibilidades de negociar penas por aceptaciones de culpabilidad.

Al igual que en el sistema inglés, el control de la discrecionalidad para acusar es político. Si se trata de un funcionario de elección del poder ejecutivo, puede ser removido; si se trata de un funcionario de elección popular, seguramente perderá la confianza del pueblo y con ello la reelección ${ }^{14}$. Por lo anterior, se puede afirmar que el control al sistema de alegaciones de culpabilidad preacordadas o negociaciones con el procesado es netamente político y por ende el "fiscal que se equivoque y en contra de la opinión pública, por ejemplo, se abstenga de procesar un asesino múltiple o un terrorista va a confrontar serios problemas con la sociedad que representa hasta el extremo que puede llegar a perder la reelección, o incluso, a ser removido de su cargo"15

\section{iii. Conclusiones respecto del sistema anglosajón}

En los sistemas anglosajones "no se menciona siquiera la expresión 'principio de oportunidad', pues en ellos la discrecionalidad para la formulación de la acusación es absoluta" 16 , por tanto no hay principio de oportunidad que sea una excepción o complemento al principio de legalidad, pues la discrecionalidad para acusar es la regla general para ejercitar la acción penal y responde a intereses de política criminal. En ambos casos, el control de dicha discrecionalidad es de carácter político y no judicial.

\subsection{Europa continental}

En Europa continental los sistemas judiciales presentan distintos matices pero el principio de legalidad u oficialidad siempre ha estado presente. No obstante, a partir de la Recomendación 18 del Comité de Ministros del Consejo de Europa, en 1987 "se le aconsejó a los países miembros contemplar esta discrecionalidad o mecanismos equivalentes de definición de prioridades en la conducción de la política criminal para contrarrestar los retrasos que sufre la administración de justicia penal en el continente" 17 .

14 Consultar fuente Mestre Ordóñez, Op. Cit.

15 Granados PeÑa, Op. Cit., p.36.

16 Aristizábal GonZÁlez, CARolina (2005). Alcance del principio de oportunidad en la nueva legislación procesal penal colombiana. Bogotá: Pontifica Universidad Javeriana, p.18. Consultar fuente http://www.javeriana.edu.co/biblos/tesis/derecho/dere7/DEFINITIVA/TESIS\%2045.pdf.

17 Mestre Ordoñez, Op. Cit. p.170. 


\section{i. Italia}

En Italia la titularidad de la acción penal fue otorgada al Ministerio Fiscal, desvinculado de los poderes políticos del Gobierno. Respecto de los representantes del Ministerio Fiscal que adelantan la acusación (fiscales) no existe una jerarquía funcional interna, lo cual significa una mayor independencia ${ }^{18}$.

En Italia la Constitución estableció en su artículo 112 la obligatoriedad del ejercicio de la acción penal. Por ende, no existe principio de oportunidad y el principio de legalidad se aplica en la medida que lo permitan las condiciones fácticas y presupuestales del Estado.

\section{ii. Alemania}

En Alemania existe un órgano encargado del ejercicio de la acción penal (Fiscalía) y rige el principio de oficialidad de la persecución penal, con algunas excepciones, como en los delitos insignificantes ${ }^{19}$, los de criminalidad leve y media o los delitos de acción privada ${ }^{20}$. Según el profesor Claus Roxin: "La fiscalía es una autoridad de la justicia que no puede ser atribuida ni al ejecutivo ni al tercer poder, sino que se trata de un órgano independiente de la administración de justicia que está entre ambos" 21 . El artículo 152 de la Ordenanza Procesal Penal de Alemania (StPo) impone el principio de obligatoriedad del ejercicio de la acción penal. Es así que a diferencia de los sistemas anglosajones, aplica el principio de legalidad entendido como el deber de la Fiscalía de "realizar investigaciones cuando existe la sospecha de que se ha cometido un hecho punible" y "formular la acusación cuando después de las investigaciones sigue existiendo esa sospecha vehemente"22.

Este principio se aplica con la finalidad de que el Estado castigue "toda violación de la ley penal" 23 . Sin embargo, la legislación alemana ha consagrado excepciones al principio de legalidad "en el ámbito de la criminalidad más leve y, en gran parte, también en la de la criminalidad media" ${ }^{24}$, pues en dichos casos debe aplicarse el principio de oportunidad.

18 Ibidem, p. 172.

19 Roxin, Claus (2000). Derecho Procesal Penal. Buenos Aires: Editores del Puerto, p. 83.

20 Ibidem, p. 85.

21 Roxin, Claus (2000). Derecho Procesal Penal. Buenos Aires, Editores del Puerto, p. 53, en José FERnANDo MESTRE ORdóÑEZ (2011). La discrecionalidad para acusar. Bogotá, Editorial Ibañez, p. 172.

22 Ibidem, p. 89.

23 Mestre OrdóñeZ, Op. Cit., p. 89.

24 Roxin, Op. Cit., p. 90. 
La StPo en su artículo sección 153 distingue cuatro grandes grupos de supuestos de hecho en los cuales la acción penal se puede sobreseer a pesar de que exista sospecha del ilícito:

A) Cuando el reproche por el hecho es insignificante y no existe ningún interés en la persecución penal ${ }^{25}$ : aquellos casos en que "un procedimiento judicial complicado aparece en muchos casos como poco conveniente" 26 "debido a que a través de ellos los intereses de la administración de justicia penal alemana son afectados solo en pequeña medida"27.

B) Cuando el interés en la persecución penal puede ser satisfecho de otro modo: este supuesto se configura en aquellos casos en que "existe un interés en la persecución penal que, sin embargo, puede ser suprimido imponiéndole al imputado condiciones e indicaciones" 28 como "la reparación de los daños y el pago de una suma de dinero a favor de una institución de utilidad pública o del fisco" 29 . En todo caso, no pueden ser ordenadas otras condiciones distintas a las señaladas en la sección 153 del StPo.

C) Cuando al interés en la persecución penal le son opuestos intereses estatales prioritarios: este supuesto ocurre cuando i) "el procedimiento generaría (...) peligro" para la seguridad del Estado; ii) "el autor ha evitado un peligro para el Estado a través de su contribución" 30; iii) se "pretende fomentar la disposición a denunciar de la víctima extorsionada o coaccionada" 31 ; iv) en aquellos casos donde se pretende "disminuir el peligro de decisiones judiciales contradictorias" $32 \mathrm{y}, \mathrm{v}$ ) "para evitar que el denunciante utilice el procedimiento penal gratuito como medio de presión" 33 .

D) Cuando el ofendido puede llevar por sí mismo la persecución penal: además de ser una excepción al principio de oficialidad de la acción penal, en la legislación alemana los delitos de acción privada pueden ser sujetos de aplicación del principio de oportunidad en aquellos casos donde la fiscalía asuma la persecución de los mismos. Además de lo anterior, según los dictados de la política criminal establecidos en la ley, la acusación puede no formularse para ciertos delitos por decisión de la fiscalía y en otros casos se requiere autorización judicial para no formularse acusación. De manera análoga, hay delitos en los que el acusador puede desistir unilateralmente de

25 Ibidem.

26 Ibidem.

27 Ibidem.

28 Ibidem, p. 92.

29 Ibidem.

30 Ibidem, p. 93.

31 Ibidem.

32 Ibidem.

33 Ibidem. 
la acusación formulada y otros supuestos en los cuales se requiere de autorización judicial para renunciar a la acusación formulada.

En ese sentido, las causales de aplicación del principio de oportunidad deben ser taxativas y la renuncia de la acción penal debe ser controlada por el juez competente.

\section{iii. España}

En España el artículo 105 de la ley de enjuiciamiento criminal establece que el ejercicio de la acción penal es obligatorio. Sin embargo, la reforma penal que se está presentando en dicho país tiene por objeto establecer la oportunidad reglada.

La elección del Fiscal es hecha por el "Rey, a propuesta del gobierno, oído el Consejo General del Poder judicial" 34 . Existe entonces una autoridad del Estado en cargada de ejercer la acción penal.

En España el principio de oportunidad "no se encuentra típicamente establecido, señalado, ni reglado de manera expresa o taxativa" 35 , por el contrario la Constitución sujeta las funciones del Ministerio Fiscal al principio de legalidad y se discute entonces si la Constitución española ha consagrado el principio de legalidad y cerrado las puertas a un principio de oportunidad ${ }^{36}$, o si por el contrario, existe la posibilidad de incorporar el principio de oportunidad dentro de la legislación española ${ }^{37}$ de manera que se haga compatible con la Constitución.

\section{iv. Conclusiones respecto del sistema europeo continental}

A diferencia del sistema anglosajón, donde la discrecionalidad para acusar y el control político a dicha facultad es la norma, la mayoría de los sistemas europeo continentales han establecido la obligatoriedad de ejercer la acción penal en respeto del principio de legalidad. En aquellos Estados donde se ha consagrado el principio de oportunidad este es reglado y su control es jurisdiccional. Por otra parte, se observa que el término "principio de oportunidad" surge en Europa continental para referirse

34 Mestre Ordoñez, Op. Cit, p.174.

35 Villanueva Meza, Javier Antonio (2005). El principio de oportunidad. Bogotá: Leyer, p. 62.

36 El artículo 124.2. dice: "El ministerio fiscal ejerce sus funciones por medio de órganos propios conforme a los criterios de unidad de actuación y dependencia jerárquica y con sujeción en todo caso, a los de legalidad e imparcialidad".

37 Sobre el debate si se debe incorporar o no el principio de oportunidad consultar fuente ARMENTA Deu, TeResA (2009). Lecciones de derecho procesal penal. Madrid: Marcial Pons, pp. 34 y ss. 
análogamente a la discrecionalidad de la acción penal, pero carece de la prevalencia que esta tiene en el sistema anglosajón.

\subsection{El principio de oportunidad en Chile}

América Latina se ha preocupado en los últimos lustros por establecer reformas a los procedimientos penales, tratando de implementar aquellos que son de corte acusatorio y la figura del principio de oportunidad. Antes de adentrarnos de manera extensa al principio de oportunidad en Colombia, consideramos conveniente referirnos al caso chileno, pues creemos conveniente que se consagre un principio de oportunidad en Colombia relativamente abierto y que subsuma una cantidad abundante y casi indeterminada de supuestos de hecho, como sucede en Chile.

En Chile, la Fiscalía se conoce como Ministerio Público y es quien, en principio, ejerce la acción penal. Sin embargo, en la legislación chilena "no existe un monopolio estatal en la formulación de la acusación" 38 pues también se "autoriza para que pueda ser ejercida por el querellante" 39 o la víctima.

En Chile está vigente el principio de legalidad u oficiosidad de la acción penal como lo indican los artículos $5 .^{\circ}$ y $6 .^{\circ}$ de la Constitución chilena ${ }^{40}$, pero este no es absoluto, pues el artículo 166 del Código Procesal Penal establece que el Ministerio Público "promoverá la persecución penal, sin que pueda suspender, interrumpir o hacer cesar su curso, salvo en los casos previstos en la ley".

El artículo 170 del CPP chileno señala:

Los fiscales del ministerio público podrán no iniciar la persecución penal o abandonar la ya iniciada cuando se trata de un hecho que no comprometiere gravemente el interés público, a menos que la pena mínima asignada al delito excediere la de presidio o reclusión menores en su grado mínimo o que se tratare de un delito cometido por un funcionario público en ejercicio de sus funciones.

La doctrina chilena entiende que lo consagrado en el artículo 170 no es una excepción, sino que es una facultad legal para aplicar un principio de oportunidad en aquellos casos donde no "se justifica iniciar o perseverar en una investigación penal, porque

38 Carocca Pérez, Alex (2009). Manual el nuevo sistema procesal penal chileno. Santiago: Thomson Reuters.

39 Ibidem.

40 Ibidem, p. 17. 
se trata de hechos de muy baja peligrosidad político criminal" 41 . Esta renuncia a la acción penal deberá hacerse mediante orden motivada, la cual debe ser comunicada al juez de garantías, quien lo notificará a los intervinientes. Así mismo, puede dejarla sin efecto cuando considere que el fiscal se ha extralimitado en sus funciones; que se está aplicando en aquellos casos en los cuales la ley no ha autorizado su aplicación; o cuando la víctima manifieste que tiene interés en ejercer la acción penal o continuarla.

\section{PRINCIPIO DE OPORTUNIDAD EN COLOMBIA}

En la doctrina nacional no hay consenso para determinar si el principio de oportunidad es un principio fundante, un complemento al principio de legalidad o una excepción al principio de legalidad ${ }^{42}$; pero si es claro el principio de oportunidad en Colombia reconoce la vigencia principio de legalidad pero busca conceder discrecional al ente acusador para iniciar o continuar con el ejercicio de la acción penal para optar por una solución alternativa al conflicto que genera el delito, ciñéndose a orientaciones de política criminal, para buscar respuestas al delito que puedan ser más útiles y convenientes que la imposición de la pena que describa la ley para un delito en particular.

\subsection{El Estado colombiano y la necesidad del principio de oportunidad}

Colombia es un Estado de derecho que, como tal, somete potestades como la persecución penal al imperio de la ley y convierte esta potestad en una competencia que debe ejercer el Estado, en la que se privilegia de una manera prevalente el principio de legalidad, ya que este es una garantía para que no haya excesos ni defectos en el ejercicio del poder estatal. En un Estado de derecho es entendible que el principio de oportunidad o la discrecionalidad de la acción penal no pueda ser más que una

41 Ibidem, p. 79.

42 Autores como KLAUS VOLK han definido el principio de oportunidad como una excepción al principio de legalidad (Guerrero, ÓsCAR Julián (2013). Fundamentos teórico constitucionales del nuevo proceso penal. Bogotá: Ediciones Nueva Jurídica, p. 132), otros como GiMENo SENDRA afirman que el hecho de que en algunas legislaciones esté reglado el principio de oportunidad implica una aplicación del principio de legalidad (Guerrero, Op. Cit., p. 133), en el ámbito nacional Perdomo TORRES afirma que el principio de oportunidad morigera y complementa el ejercicio del principio de legalidad para aplicar una medida político-criminal más adecuada a determinado conflicto ocasionado por un hecho punible (PERdomo TORRes, Jorge Fernando (2005). Los principios de legalidad y oportunidad. Fundamentos constitucionales y teórico penales, y su regulación en el derecho procesal penal colombiano. Bogotá: Universidad Externado de Colombia, pp. 43 a 46) y el profesor GómEZ PAVAJEAU afirma que el principio de oportunidad es un principio de rango constitucional que se debe aplicar, aplicando exámenes de proporcionalidad y razonabilidad (GómEz PAVAJEAU, CARLOS (2016). La oportunidad como principio complementario del proceso penal. Bogotá: Editorial Nueva Jurídica, p. 67). 
excepción o incluso un desconocimiento al principio supremo de la estricta legalidad, pero en el marco de un Estado social y democrático de derecho como el colombiano ${ }^{43}$ el principio de estricta legalidad, propio de un Estado de derecho, se debe ponderar y en ocasiones debe ceder.

El Estado colombiano es un Estado social, como lo prevé la Constitución ${ }^{44}$, lo que implica que es un propósito del Estado solucionar de manera eficiente las problemáticas propiciadas por las relaciones sociales de los individuos ajenas a la acción del Estado y propender por la satisfacción del interés general ${ }^{45}$; también es una república democrática, participativa y pluralista, y esto conlleva a que se propenda porque la sociedad y los individuos participen en la ejecución y el diseño de las políticas y las instituciones del Estado ${ }^{46}$. Por otra parte, nuestro Estado tiene una apertura a la integración a la comunidad internacional y reconoce la vigencia del derecho internacional, de hecho, desde la Constitución se reconoce que los deberes fundamentales del Estado deben estar conformes a los tratados internacionales de derechos humanos que vinculan a Colombia ${ }^{47}$, estableciendo de esta forma que las actividades más importantes y fundamentales del Estado no pueden desconocer ni infringir los tratados internacionales de derechos humanos porque estos tratados son unos límites infranqueables que no puede desbordar la actividad del Estado y porque son los puntos de acuerdo más importantes y fundamentales a los que ha llegado nuestro Estado con la comunidad internacional y que posibilitan su integración con un mundo globalizado.

Consideramos que el proceso penal debe estar irradiado en todas sus instituciones por los principios y valores que inspiran al Estado y en ese sentido en el marco de un Estado como el colombiano el proceso penal no se puede ceñir únicamente al principio de legalidad estricto y debe propender por la solución de los conflictos sociales que crea el delito, la satisfacción del interés general, la participación de la comunidad y los individuos en el proceso penal y el respeto de los tratados internacionales de derechos humanos. Para cumplir estos fines es necesario en ciertos casos renunciar al ejercicio de la acción penal y a la estricta legalidad y buscar una respuesta alternativa al conflicto, esto se logra con la aplicación del principio de oportunidad. En este sentido, en el marco de un Estado social y democrático de derecho abierto a la globalización como el nuestro, el principio de oportunidad, entendido como una institución procesal que sanciona y reprime la delincuencia y permite la participación

43 Artículo 1. Constitución Política.

44 Artículo 1. Constitución Política.

45 Villar Borda, Luis (2007). "El Estado de Derecho y Estado Social de Derecho", en Revista Derecho del Estado, n. ${ }^{\circ}$ 20, diciembre de 2007, Bogotá: Universidad Externado de Colombia, pp. 73-96.

46 Younes Moreno, Diego (2014). Derecho Constitucional Colombiano, 13 ed. Bogotá: Legis, pp. 71-78.

47 Artículos 9 y 93, entre otros. 
del delincuente, la comunidad y la víctima para la solución de un conflicto criminal, no puede ser concebido como la negación o excepción al principio de legalidad, sino un complemento al mismo para hacer eficaces las cláusulas de social y democrático que tiene nuestro Estado de derecho en los casos en los que la imposición de la pena no tenga la misma eficiencia que una medida sancionatoria distinta. Por tanto, el principio de oportunidad no puede tener el carácter de excepcional sino debe ser considerado un principio o mandato de optimización que se aplique de manera armónica con el principio de legalidad cuando este no pueda ser tan provechoso socialmente y eficiente.

En Colombia es obligación de la Fiscalía adelantar la correspondiente acusación de los delitos puestos en su conocimiento, pero el principio de oportunidad es la facultad que tiene el ente acusador de disponer de manera permanente o temporal de la acusación para renunciar, suspender o interrumpir la acción penal ${ }^{48}$ y aplicar una medida político-criminal más adecuada para resolver un conflicto suscitado por un delito.

Dicho lo anterior, resulta claro que el principio de oportunidad no significa impunidad autorizada, tampoco una infracción al derecho a una tutela judicial efectiva y a la eficacia de la administración de justicia ni una forma de lograr el archivo de una investigación penal ${ }^{49}$, sino que es una medida sancionatoria ${ }^{50}$ aplicada en el marco de la política criminal del Estado para i) administrar justicia y realizar los fines del proceso penal de una manera más flexible, adecuada, razonable y socialmente útil en un caso concreto; ii) obtener un tutela judicial efectiva de los derechos de los intervinientes en el proceso penal; iii) racionalizar y priorizar los esfuerzos del Estado al momento de perseguir el delito penalmente y iv) propiciar la intervención del acusado, la sociedad y la víctima en la resolución de los conflictos y la ejecución de la política criminal.

\subsection{Normas constitucionales que fijan derroteros del principio de oportunidad}

El principio de oportunidad se debe ceñir al menos a unos límites que imponen ciertas normas constitucionales. Entre ellas debemos resaltar:

Artículo 250. La Fiscalía General de la Nación está obligada a adelantar el ejercicio de la acción penal y realizar la investigación de los hechos que

48 Constitución Política, artículo 250.

49 Urbano Martínez, José JoAquín (2006). "Los fines constitucionales del proceso penal como parámetros de control del principio de oportunidad", en Revista Derecho Penal y Criminología, Vol. 27, n. ${ }^{\circ}$ 80, enero-junio de 2006. Bogotá: Universidad Externado de Colombia, pp. 121 a 125.

50 Gómez Pavajeau, Op. cit, pp. 296 y 297. 
revistan las características de un delito que lleguen a su conocimiento por medio de denuncia, petición especial, querella o de oficio, siempre y cuando medien suficientes motivos y circunstancias fácticas que indiquen la posible existencia del mismo. No podrá, en consecuencia, suspender, interrumpir, ni renunciar a la persecución penal, salvo en los casos que establezca la ley para la aplicación del principio de oportunidad regulado dentro del marco de la política criminal del Estado, el cual estará sometido al control de legalidad por parte del juez que ejerza las funciones de control de garantías (...).

En ejercicio de sus funciones la Fiscalía General de la Nación, deberá: (...)

7. Velar por la protección de las víctimas, los jurados, los testigos y demás intervinientes en el proceso penal, la ley fijará los términos en que podrán intervenir las víctimas en el proceso penal y los mecanismos de justicia restaurativa (...).

Artículo 229. Se garantiza el derecho de toda persona para acceder a la administración de justicia (...).

Artículo 93. Los tratados y convenios internacionales ratificados por el Congreso, que reconocen los derechos humanos y que prohiben su limitación en los estados de excepción, prevalecen en el orden interno.

Los derechos y deberes consagrados en esta Carta, se interpretarán de conformidad con los tratados internacionales sobre derechos humanos ratificados por Colombia.

Artículo 44. Son derechos fundamentales de los niños: (...)

Los derechos de los niños prevalecen sobre los derechos de los demás.

De lo dicho hasta el momento conviene fijar los siguientes postulados del principio de oportunidad:

1. El principio de oportunidad no está consagrado en la Constitución como una alternativa excepcional al deber de perseguir los delitos. Se debe observar que el artículo 250 no está redactado de forma que permita entender al principio de oportunidad como una excepción pues le advierte a la Fiscalía que "no podrá, en consecuencia, suspender, interrumpir, ni renunciar a la persecución penal, salvo en los casos que establezca la ley para la aplicación del principio de oportunidad", y esto no indica que la aplicación del principio de oportunidad sea una alternativa excepcional. Si el constituyente hubiera querido establecer el principio de oportunidad como una excepción a la legalidad, lo 
hubiera redactado de esa forma y sin ambages, pero no se hizo de esa manera, por tanto no hay motivo para pensar que es de aplicación excepcional ${ }^{51}$.

Además de esto, el tipo de Estado que es Colombia (social, democrático, participativo y pluralista) indica que la aplicación del principio de oportunidad en el proceso penal es una necesidad y no una excepción pues, como se indicó anteriormente, con el principio de oportunidad se alcanzan fines que no se satisfacen eficientemente con la imposición de una pena.

2. Según la Constitución Política las causales de procedencia del principio de oportunidad deben ser reguladas en la ley ${ }^{52}$. El principio de oportunidad como el de legalidad son manifestaciones legítimas del Estado y el hecho de que su procedencia siga parámetros legales es una garantía de que se va a aplicar sin arbitrariedad ni discriminación por parte de quien detenta la titularidad de la acción penal.

De esto se desprende que aunque es conveniente ilustrarnos de doctrinas foráneas, resulta inadmisible para nosotros una discrecionalidad plena como la que se observa en el sistema anglosajón.

3. El principio de oportunidad debe estar precedido por la formulación de una política criminal por parte del Estado y debe ser concebido como una forma de desarrollo o ejecución de dicha política criminal ${ }^{53}$.

4. El principio de oportunidad debe ser objeto de control judicial para asegurar que se cumpla el debido proceso, no se conculquen los derechos de las víctimas, que se apliquen en lo posible y de forma razonable el derecho sustancial y los fines del derecho penal y del proceso penal, que no se deniegue justicia y se garantice en la medida de lo posible una tutela judicial efectiva ${ }^{54}$.

5. El principio de oportunidad no puede ser una negación al derecho a una tutela judicial efectiva en materia penal ni una imposibilidad al acceso a una correcta administración de justicia, por consiguiente su realización en el proceso penal debe consultar los intereses de la víctima del delito por el cual se

51 Gómez Pavajeau, Carlos Arturo (2016). "En defensa y promoción del principio de oportunidad", en Balance crítico del sistema acusatorio a los diez años de su vigencia. Bogotá: Defensoría del Pueblo.

52 Urbano Martínez, José Joaquín (2003). "El principio de oportunidad en el proyecto de Código de Procedimiento Penal -Estado actual-“", en Revista Derecho Penal y Criminología, Vol. 24, n. 74 , Bogotá:Universidad Externado de Colombia, pp. 195-208.

53 Ibidem, p. 207.

54 Daza GonzÁlez, Alfonso (2011). La discrecionalidad en el ejercicio de la acción penal frente a los fines del proceso penal en el Estado Social de Derecho. Bogotá: Universidad Libre, p. 81 
inició el proceso penal y permitir su participación y eventual contradicción ${ }^{55}$, sin que ello implique someter el ejercicio de la acción penal a los intereses de la víctima en todos los casos.

6. Los tratados internacionales de derechos humanos aprobados por Colombia están por encima de cualquier decisión política o discrecional del Estado; y por tratados internacionales de derechos humanos no están comprendidos solamente los que consagran o conceden derechos humanos sino los que prevén $\mathrm{y}$ ordenan tomar medidas que protejan y prevengan las distintas violaciones de derechos humanos como lo son los tratados que ordenan proteger los derechos humanos, prescribiendo a los Estados prevenir, investigar y sancionar las graves violaciones de derechos humanos y los crímenes internacionales ${ }^{56}$.

Por esto el principio de oportunidad en ningún supuesto podrá ser una herramienta para evadir los deberes de investigar, acusar, sancionar y prevenir las graves violaciones a derechos humanos y delitos que impliquen graves violaciones contra el $\mathrm{DIH}^{57}$.

7. Los derechos de los niños, niñas y adolescentes prevalecen sobre las inclinaciones de política criminal del Estado y el principio de legalidad, por ello consideramos que el principio de oportunidad en delitos contra menores de edad sería constitucionalmente admisible, siempre y cuando se garantice que con la aplicación del principio de oportunidad la protección de los derechos de las víctimas niños, niñas y adolescentes será mayor que con el ejercicio del principio de legalidad.

Una vez fijados algunos postulados importantes del principio de oportunidad se debe reiterar que este principio, tal como está fijado en la Constitución, no es excepcional, sin embargo, debe aplicarse de acuerdo a criterios fijados en la ley y someterse a un control judicial para evitar de esta forma la arbitrariedad en la discrecionalidad de la acción penal. También huelga repetir que el principio de oportunidad es una sanción a una conducta punible en el marco de una política criminal no una forma de ahorrarse trabajo por parte de la Fiscalía por tanto se entiende que el mismo es una forma más inteligente y útil de tutela judicial efectiva.

55 URbano MARTíneZ, José JoAquín (2006). "Los fines constitucionales del proceso penal como parámetros de control del principio de oportunidad”, en Revista Derecho Penal y Criminología, Vol. 27, n. ${ }^{\circ}$ 80, enero-junio de 2006. Bogotá: Universidad Externado de Colombia, pp. 121 a 125.

56 GutiérRez BELTRÁn, ANDRÉs (2007). El bloque de constitucionalidad, conceptos y fundamentos. Bogotá: Universidad Externado de Colombia, pp. 67 y 68.

57 Corte Constitucional, Sentencia C-648 de 2006. 


\subsection{Regulación del principio de oportunidad en la Ley 906 de 2004}

A parte de la regulación que tiene el principio de oportunidad en la Constitución, la Ley 906 de $2004^{58}$ prevé las causales por las cuales procede el principio de oportunidad (artículo 324), sus modalidades (interrupción, suspensión y renuncia de acción penal), las condiciones que debe cumplir el procesado en los casos que se suspenda la acción penal (artículo 326) e impone que el principio de oportunidad esté sujeto a la regulación que dicte la Fiscalía General de la Nación, por tanto para saber la forma en que opera y funciona es necesario referirnos al CPP y la reglamentación de la Fiscalía.

Consideramos que aunque la Constitución prevé un marco institucional para que el principio de oportunidad no se tenga como una excepción, en la ley tiene una regulación como si fuera excepcional ${ }^{59}$, pues autoriza a los fiscales de conocimiento a aplicar directamente el principio de oportunidad en los delitos con pena máxima inferior a seis años de prisión pero los despoja de esa autorización en los delitos con pena máxima superior a seis años de prisión, es decir, en los únicos en los que en la práctica la Fiscalía presta atención por exceso de trabajo (aunque esta situación cambia con la Resolución 2370 de 2016 de la Fiscalía, como se verá más adelante) ${ }^{60}$. Además de ello, restringe el principio de oportunidad a unas causales muy precisas que en la práctica impide que abarque un gran número de delitos que podrían resolverse eficientemente aplicando el principio de oportunidad.

Observamos que no es posible explicar la aplicación del principio de oportunidad sin remitirnos a la forma como la Fiscalía General ha regulado el tema, por ello se hará un breve recuento de la regulación que la Fiscalía ha dispuesto para el principio de oportunidad:

\section{Resoluciones 6658 y 6657 de 2004}

Esta normativa establece la aplicación del principio de oportunidad como una excepción y dispuso que el Fiscal General designaría a los coordinadores de Unidades Delegadas ante Tribunales Superiores de Distrito para la aplicación del principio de oportunidad cuando se trate de delitos con pena máxima superior a seis años o del

58 Artículos 321 y siguientes.

59 “Artículo 322. Legalidad. La Fiscalía General de la Nación está obligada a perseguir a los autores y partícipes en los hechos que revistan las características de una conducta punible que llegue a su conocimiento, excepto por la aplicación del principio de oportunidad, en los términos y condiciones previstos en este código".

60 El hecho de que el fiscal de conocimiento no pueda aplicar directamente el principio de oportunidad, implica que este deba adelantar un trámite engorroso al interior de la fiscalía para que otro funcionario autorice la aplicación del principio de oportunidad. Esto hace que sea más desgastante el trámite del principio de oportunidad que el proceso mismo y que se desincentive su aplicación. 
coordinador de la Unidad de Fiscalía Delegada ante la Corte Suprema de Justicia cuando se trate de casos de conocimiento de las Unidades Nacionales de Fiscalía, pero respecto de las causales previstas en los numerales 2, 3, 4, 5 y 9 del artículo 324 de la Ley 906 de 2004 el Fiscal General conocería siempre de la aplicación del principio de oportunidad. A pesar de lo anterior le correspondería al fiscal de conocimiento defender el control de legalidad del principio de oportunidad aplicado por otros funcionarios.

Esto hacía paquidérmico y demorado el trámite de un principio de oportunidad porque requería articular el conocimiento que tiene el fiscal del caso, quien tomaba la iniciativa para la aplicación del principio de oportunidad y la facultad de decisión asignada a un funcionario de mayor jerarquía.

Entre otras disposiciones esta normatividad también previó que las modalidades del principio de oportunidad de suspensión e interrupción de la persecución penal son, por regla general y de acuerdo a la naturaleza de la situación, las etapas preparativas para la renuncia de la persecución penal.

\section{Resolución 6618 de 2008}

En el año 2008 se expide la Resolución 6618 que tenía por objeto reglamentar la aplicación del principio de oportunidad para desmovilizados de grupos armados al margen de la ley en el marco de la Ley 975 de 2005. Esta Ley se expidió con el objeto de dictar las disposiciones necesarias para que estos grupos pudieran reincorporarse a la sociedad y de esta forma contribuir a la consecución efectiva de la paz. En virtud de esto, la Resolución estableció que por unidad de materia en el tema de desmovilizados, economía procesal, eficiencia y eficacia de la administración de justicia la Unidad Nacional de Fiscalías para la Justicia y la Paz era la competente para conocer la aplicación del principio de oportunidad para miembros de grupos armados al margen de la ley que se hubieren desmovilizado. Sin embargo, la presente Resolución nuevamente concibe el principio de oportunidad "como excepción al principio de legalidad"61 lo que evidencia que el tratamiento que se le da al principio de oportunidad es el de una excepcionalidad y no realmente el de un principio.

Esta Resolución le dio mayor fluidez al principio de oportunidad para esta clase de casos, pues estableció que los fiscales adscritos a esta unidad sean delegados especiales del Fiscal General de la Nación para darle aplicación al principio en los delitos de su competencia, lo que fomentó que, para esta clase de procesos, los fiscales de conocimiento fueran quienes aplicaran el principio de oportunidad.

61 Resolución 6618 de 2008. Considerandos. 


\section{Resolución 3884 de 2009}

La Resolución 3884 de 2009 tuvo por objeto la modificación y adición de las Resoluciones 6657 y 6658 de 2004, buscando la aclaración del procedimiento interno para la aplicación del principio de oportunidad con miras a su eficaz aplicación.

Entre las modificaciones que se introducen con esta Resolución se resalta que la aplicación directa del principio de oportunidad por parte del Fiscal General de la Nación obedece a los eventos que se relacionen con las causales $2,3,4$ y 8 , no ya $2,3,4,5$ y 9 , y no se hace mención al requisito de que el delito debe tener como condena un máximo superior a seis años de pena privativa de la libertad.

Se ordena la conformación de un grupo integrado por servidores de la entidad bajo la coordinación de la Dirección Nacional de Fiscalías, con el fin de que se lleve un control adecuado de la aplicación de dicha figura y poder medir los estándares de eficiencia. Así, el grupo debe recibir, registrar y consolidar los informes que busquen la posibilidad de la aplicación de un principio de oportunidad para un caso concreto y posteriormente recibir y consolidar los informes que las aplicaciones efectivas, ya sea por parte del Fiscal General, sus delegados especiales o por los fiscales de conocimiento.

Se establece además, notificar a la víctima del propósito de aplicar este beneficio y darle la oportunidad de que comunique sus inquietudes o pretensiones.

Por último, para los eventos de delitos que se sancionen con pena privativa de la libertad y que excedan el límite máximo de seis años, el Fiscal General podrá designar un delegado especial en el Jefe de la Unidad Delegada ante el Tribunal Superior para la aplicación del principio de oportunidad. Para los numerales ya mencionados, el Fiscal podrá hacer uso de su facultad de sustitución en el Jefe de la Unidad Delegada ante la Corte Suprema de Justicia para la aplicación del principio en los casos que sean competencia de las Unidades Nacionales de Fiscalía.

\section{Resolución 692 de 2012}

La Resolución 692 de 2012 se encargó de modificar la Resolución 6658 de 2004, en lo concerniente a la aplicación del principio de oportunidad para los delitos sancionados con pena privativa de la libertad que exceda de seis años como límite máximo, considerando que en las jefaturas de las Unidades Delegadas ante los Tribunales Superiores existía represamiento en el trámite de las solicitudes de principio de oportunidad, por ello se distribuyó entre todos los fiscales que conformaban estas unidades su aplicación, propiciando de esta manera un desempeño más eficiente en la aplicación de este instrumento. 
De esta forma se evidencia que la modificación normativa surge de la necesidad de distribuir en un mayor número de funcionarios de la Fiscalía la labor de aplicación del principio de oportunidad, desconcentrando esa función de altos funcionarios ajenos y lejanos al problema social que suscita determinado delito.

\section{Resolución 1168 de 2014}

La presente Resolución motiva su decisión en primera medida en el mandato constitucional del artículo 250 y en el artículo 323 de la Ley 906 de 2004, modificado por la Ley 1312 de 2009. A diferencia de las resoluciones anteriores, esta no se refiere al principio de oportunidad como una excepción al principio de legalidad. Retoma las Resoluciones 0-6657 y 0-6658, en cuanto a la reglamentación que se expidió del procedimiento para la aplicación del principio de oportunidad, y la Resolución 3884 de 2009 para los eventos de la aplicación de las causales previstas en los numerales 2, 3, 4 y 8, y de la designación del Fiscal Jefe Delegado ante la Corte Suprema de Justicia como delegado especial para los delitos que se sancionan con pena privativa que en su máximo exceda los seis años.

Se adecua la regulación a la modificación de la estructura orgánica y funcional de la Fiscalía General que trajo el Decreto 016 del 9 de enero de 2014, creándose las Direcciones de Fiscalías Nacionales y de Fiscalías Nacionales Especializadas, la Dirección Nacional del Sistema Penal Acusatorio y la Articulación Interinstitucional en Materia Penal, dentro de la cual se encuentra el Grupo de Mecanismos de Terminación Anticipada y Justicia Restaurativa, encargado del seguimiento, la estadística y las políticas de gestión de la aplicación de los principios de oportunidad. De acuerdo con esto se hace necesario designar un delegado especial para la aplicación del principio en situaciones especiales.

Se resuelve entonces la designación especial de un delegado del Fiscal General de la Nación en cabeza del coordinador del mencionado Grupo para la aplicación del principio de oportunidad en el caso de delitos cuya sanción privativa de la libertad exceda el límite máximo de seis años, en los casos que conocen los Fiscales adscritos a la Dirección de Fiscalías Nacionales, Dirección de Fiscalías Nacionales Especializadas y Fiscales Delegados ante la Corte Suprema de Justicia.

De esta forma se evidencia que la Resolución 1168 de 2014 no regula aspectos sustanciales del principio de oportunidad, únicamente se encarga de reglamentar lo atinente a quién es el funcionario encargado de la aplicación de este principio para delitos que excedan de seis años en su máximo, en circunstancias muy específicas.

\section{Resolución 2370 de 2016}

Recientemente se expidió la Resolución 2370 que reglamenta nuevamente la aplicación del principio de oportunidad, derogada todas las resoluciones anteriores y 
establece un solo cuerpo normativo que actualiza y unifica la regulación interna para la aplicación de esta herramienta.

Al igual que en la Resolución 1168, se transcribe el artículo 250 de la Constitución Política de Colombia y no se hace mención al principio de oportunidad como excepción al principio de legalidad. Se hace énfasis en la sujeción del principio de oportunidad y su aplicación a la política criminal del Estado y de cómo el Fiscal General de la Nación debe desarrollar ese mandato constitucional y legal.

Se evidencia una especial consideración por la constitucionalización del principio y el respeto por los derechos fundamentales, en la medida en que, siguiendo jurisprudencia de la Corte Constitucional, se evidencia la necesidad de que el principio de oportunidad se aplique de forma coherente con el orden constitucional, los deberes fundamentales del Estado y tenga en cuenta los intereses de los intervinientes en el proceso penal. Entre los aportes a la concepción del principio de oportunidad se encuentra la necesidad de aplicar el principio de proporcionalidad para sopesar la utilidad de aplicar el principio de legalidad o el de oportunidad:

Artículo 2. El principio de oportunidad es un instrumento constitucional de la política criminal del Estado, cuya consagración y aplicación solo es posible mediante la ponderación de los intereses del Estado, de la sociedad y de los intervinientes en el proceso penal. La aplicación del principio de oportunidad debe estar fundamentada siempre en el desarrollo de los criterios de adecuación, necesidad y proporcionalidad en sentido estricto, propios de la técnica de la ponderación. En su aplicación se presume el respeto por el principio de justicia.

Parágrafo. No se concederán inmunidades totales, salvo cuando el beneficio obtenido para la justicia, la sociedad y las víctimas sea significativamente superior al obtenido por el procesado.

De esta forma se evidencia la creciente evolución desde la perspectiva de la Fiscalía General de la Nación del principio de oportunidad como una herramienta sujeta a la política criminal del Estado en protección del principio de justicia que enmarca el proceso penal en el ordenamiento colombiano. Además, es evidente la tendencia a la constitucionalización del derecho penal y su sujeción al respeto por los derechos fundamentales. El reconocimiento del principio de proporcionalidad y el uso de la técnica de la ponderación reconoce que nuestro ordenamiento se compone de principios, entre otros aspectos, que pueden entrar en colisión y es necesario sopesar, para un caso determinado, cuál debe propender sobre el otro.

El hecho de aplicar el principio de proporcionalidad para aplicar el principio se le reconoce el carácter de mandato de optimización, sin embargo este mandato se activa con una decisión discrecional del ente acusador mas no es una obligación permanente y de obligatoria activación cuando las condiciones para su aplicación se cumplan. 
La Resolución 2370 de 2016 advierte que "el principio de oportunidad se aplica en las modalidades de: i) Interrupción, ii) Suspensión o iii) Renuncia” y las modalidades de interrupción y suspensión son preparativas de la renuncia, pero se faculta al acusador a renunciar a la persecución penal sin que previamente se haya interrumpido o suspendido. Se puntualiza que en la modalidad de interrupción no se imponen condiciones para la aplicación del principio de oportunidad, mientas que en la suspensión sí se imponen y se suspende la persecución penal por un tiempo determinado para que estas condiciones se puedan cumplir hacia renunciar al ejercicio de la acción penal. Cuando el principio de oportunidad se aplica bajo la modalidad de renuncia se entiende que desiste de la acción penal y tiene como consecuencia la extinción de la acción penal para esos hechos determinados, previa comprobación del juez de control de garantías.

En los dos primeros eventos los términos procesales y el término de la acción penal se suspenden, contado a partir de la fecha de la legalización de su aplicación ante un juez de control de garantías.

Con la expedición de esta Resolución, el Fiscal General de la Nación tiene la facultad de asumir preferentemente la competencia para conocer cualquiera de los procedimientos sin perjuicio de la etapa en la que se encuentren. La Dirección Nacional del Sistema Penal Acusatorio y de la Articulación Interinstitucional en Materia Penal ejercerá la coordinación y el seguimiento del procedimiento y aplicación del principio de oportunidad.

El tema de la competencia no evidencia mayores cambios en la medida en que el Fiscal General de la Nación sigue siendo el competente para conocer de manera exclusiva aquellos casos en donde se apliquen las causales $2,3,4,5$ y 8 y se especifica que los acercamientos para la posible aplicación no son vinculantes para ser adoptados. Sin embargo, para aquellos delitos sancionados con pena privativa de la libertad que tenga un límite máximo superior a seis años, la aplicación será delegada a los fiscales locales, seccionales, especializados, de la Unidad de Fiscalías de Infancia y Adolescencia, delegados ante el Tribunal y delegados ante la Corte Suprema de Justicia para aquellos casos que sean de su competencia; a los fiscales de la Dirección de Fiscalías Nacionales Especializadas de Justicia Transicional, cuando se invoque la causal 16 del artículo 324 de la Ley 906 de 2004 y el jefe de la Dirección lo autorice. Para aquellos delitos que no excedan ese límite de seis años, se aplicará el principio de manera directa por el fiscal de conocimiento, quien será el encargado de legalizarlo ante un juez de control de garantías.

Por último, recalca la importancia de las víctimas dentro del procedimiento de aplicación de principio de oportunidad pues "en la audiencia de legalización de la aplicación del principio de oportunidad, el fiscal de conocimiento deberá mostrar que la víctima tiene conocimiento sobre su celebración, sus efectos y su contenido”. 
Analizadas las anteriores Resoluciones -y como se verá en el bajo número de procedimientos para la aplicación del principio de oportunidad que se encuentra tabulado en el anexo de este trabajo-, se puede establecer que la Fiscalía ha evolucionado en cuanto a la concepción que se tiene del principio de oportunidad en la medida en que se reconoce su naturaleza como herramienta constitucional que debe estar enmarcada dentro de la política criminal del Estado.

Con la derogación de las Resoluciones 0-6657 y 0-6658 de 2004, 0-6618 de 2008 , 0-3884 de 2009, 692 de 2012, 919 de 2014 y 1168 de 2014 y la expedición de esta nueva Resolución, se muestra una tendencia por establecer un trámite más simplificado del principio de oportunidad, dejándole al Fiscal competente una mayor autonomía a la hora de decidir si aplica o no dicha figura. Vista la figura desde esta perspectiva, se puede establecer que se adecua más a los fines perseguidos de la realización de una justicia más expedita y eficaz.

Es claro que existen limitaciones al poder de disposición que tiene la Fiscalía General de la Nación. Sin embargo, al ser la pretensión penal un asunto de interés público, este debe estar debidamente regulado y controlado por el ente correspondiente. Sobre este asunto, el artículo 250 de la Carta Superior consagra la existencia de un control jurídico de legalidad, llevado acabo por parte del juez de control de garantías, incluido el trámite de principio de oportunidad.

La Resolución 2370 introduce también un cambio importante para tener una distribución más organizada de la aplicación del principio entre los funcionarios del ente acusador y para que la herramienta sea realmente eficiente. En la medida en que se simplifica el procedimiento de la aplicación de este mecanismo se puede pensar que servirá como incentivo para que los fiscales acudan realmente a su uso.

Frente a este punto se evidencia que en los últimos cinco años, y probablemente de forma constante en años anteriores, el uso del principio de oportunidad es realmente bajo (ver anexo). En zonas alejadas de la capital, e inclusive en lo concerniente al Nivel Central, los números disminuyen, tanto que la aplicación se vuelve cercana a nula. Con la expedición de esta nueva Resolución y con la unificación del procedimiento se esperaría que el uso del principio de oportunidad como correspondiente al principio de legalidad y no como su excepción, aumente. Aún más cuando se establece que debe ser la proporcionalidad y la ponderación, en sujeción a la política criminal del Estado, lo que debe determinar su uso.

Podemos señalar, en consecuencia:

1. El principio de oportunidad no es una excepción sino un mandato de optimización que se debe aplicar por discrecionalidad pero en la medida de lo posible; y si bien es una medida de economía procesal su principal finalidad debe ser la de materiali- 
zar los valores de social y de democrático, participativo y pluralista del Estado y el principio de derecho prevalente de los niños, niñas y adolescentes.

2. Si bien se indicó que el principio de oportunidad es una herencia de los sistemas procesales adversariales, consideramos que aunque los sistemas de Inglaterra y Estados Unidos, que son los adversariales por antonomasia, conciben lo discrecional de la persecución penal como una característica inherente a la forma de tramitar la acción penal, se observa que, por mandato constitucional expreso, el principio de legalidad es un principio fundante y es la forma en que se deben tramitar los hechos punibles puestos en conocimiento de la Fiscalía, en principio.

Por tanto creemos que no es admisible constitucionalmente dar plena discrecionalidad de la acción penal a la Fiscalía ni impulsar una reforma para que lo haga, pues, si el ente acusador desea no aplicar el principio de legalidad en determinados delitos debe justificar esa decisión y ponderar los intereses del Estado en la persecución penal de los delitos, de tal forma que con el principio de oportunidad se satisfagan las cláusulas de social, democrático, participativo y pluralista del Estado y los derechos prevalentes de los niños de manera proporcional y se respeten los tratados internacionales de derechos humanos.

3. La Constitución también impone unos requisitos al ejercicio de la discrecionalidad de la acción penal por parte de la Fiscalía como lo son acatar una política criminal establecida, someter la discrecionalidad a unas causales legales, tener en cuenta los intereses de las víctimas de los delitos objeto de discrecionalidad, someter la decisión del principio de oportunidad a control judicial, cumplir los tratados internacionales de derechos humanos y satisfacer el principio de derechos prevalentes de los niños, niñas y adolescentes.

4. El principio de oportunidad está concebido como principio en la Constitución, pero la Ley 906 y la reglamentación de la Fiscalía le han dado un tratamiento más restringido, por tanto es necesario adecuar la ley y la reglamentación de la fiscalía para contemplar el principio de oportunidad como un mandato de optimización, como se ha venido haciendo en la Resolución 2370 de 2016 de la Fiscalía de manera exigua.

Por lo anterior consideramos que para tramitar el principio de oportunidad como un mandato de optimización la ley se debe adecuar a la constitución, previendo unas causales más abiertas y un procedimiento más fluido.

\section{PROPUESTAS PARA HACER MÁS EFICIENTE LA FIGURA}

Una vez clara la fundamentación mínima del principio de oportunidad, procederemos a enunciar propuestas de mejora para que este principio se entienda como un mandato de optimización y una herramienta político-criminal que requiere una abundante 
aplicación; sobre todo, para que se aplique de una forma más fluida y descomplicada el principio de oportunidad.

\subsection{Propuestas para interpretar adecuadamente la naturaleza del principio de oportunidad}

Reconocer, como se ha hecho anteriormente, que el principio de oportunidad es un principio y no una excepción, ya que de la Constitución no se infiere que el principio de oportunidad se trate como una excepción. Sin embargo, para ello se debería:

- Cambiar la percepción del principio de oportunidad y no concebirlo principalmente como una herramienta para descongestionar la Fiscalía, sino como una forma más flexible de obtener la protección de los derechos de los intervinientes en un proceso penal, solucionar conflictos sociales y proteger el interés general del Estado y de la sociedad.

De igual forma se debe considerar que el principio de oportunidad es una manifestación del poder represivo y sancionatorio del Estado que se adecua a las necesidades de la sociedad y que abandona la rigidez del procedimiento ordinario para encontrar soluciones más efectivas para tutelar derechos, encontrar la verdad material de los hechos ocurridos y cumplir la política criminal del Estado.

- Hacer una redacción más afortunada del artículo 322 del CPP para que no quede asomo de duda de que el principio de oportunidad no es una excepción; y por el contrario, se incentive la aplicación de dicho principio.

- Establecer causales de procedencia del principio de oportunidad más abiertas e indeterminadas que subsuman muchos más supuestos de hecho en los que se pueda configurar una causal de procedencia del principio de oportunidad.

- Configurar una causal abierta para que la Fiscalía con base en criterios de conveniencia, necesidad, razonabilidad, proporcionalidad y humanidad pueda conceder la suspensión, interrupción o extinción de la acción penal e imponer sanciones y compromisos de comportamiento a los imputados o acusados aplicando el principio de oportunidad.

De esta manera se observará el principio de oportunidad como un intento de adecuar el ejercicio de la acción penal a las necesidades de la sociedad y no a la aplicación mecánica de una causal legal.

- Aunque una de las finalidades de este principio es propiciar una economía procesal, hemos afirmado categóricamente que el principio de oportunidad busca salidas político-criminalmente más útiles para luchar contra la criminalidad, por tanto con- 
sideramos que se debería permitir en todas las causales la aplicación del principio de oportunidad, en todas las etapas del proceso, incluso antes de la lectura del fallo de primera o segunda instancia. Es necesario aclarar que si se iniciara un principio de oportunidad cuando ya ha habido un desgaste de los órganos judiciales y se ha agotado casi todo el proceso, solo sería admisible iniciarlo si las consecuencias político-criminales son significativamente provechosas.

También vemos con buenos ojos que se permita en la ejecución de la pena buscar soluciones político-criminales alternativas a la prisión, análogas al principio de oportunidad. Sin embargo, este sería un tema ajeno a lo discrecional de la persecución penal del ente acusador y del objeto de este trabajo, por tanto se podrá debatir en otro estudio.

- No cerrar las puertas de la aplicación del principio de oportunidad para los delitos cometidos contra menores de edad, sino hacer un examen de ponderación para determinar cuándo una pena o una sanción alternativa trae más utilidad al interés superior de los niños, niñas y adolescentes víctimas.

- Tener en cuenta como finalidad fundamental del principio de oportunidad la protección de los derechos de la víctima y obligar al procesado a pagar una reparación razonable y estimada motivadamente por la Fiscalía cuando sea exigible, pero no supeditar la procedencia del principio de oportunidad a la reparación integral de la víctima según su satisfacción en ninguna causal, pues esto convertiría a la víctima en la dueña de la aplicación del principio de oportunidad y no a la Fiscalía.

Exigir la reparación integral y a satisfacción de la víctima para que proceda la renuncia de la persecución penal degeneraría el principio de oportunidad en una forma de presión de cobrar perjuicios y haría posible que la víctima haga nugatoria la aplicación del principio de oportunidad oponiéndose al monto de reparación estimado por la Fiscalía y exigiendo una reparación desproporcionada.

Se debe dejar claro que la víctima tendrá la posibilidad de exigir lo que considera que se le debe pagar ante la jurisdicción civil si considera que la reparación obtenida con el principio de oportunidad es insuficiente.

- La causal 9 del artículo prescribió con gran tino que en delitos “contra bienes jurídicos de la administración pública o de la recta administración de justicia, cuando la afectación al bien jurídico funcional resulte poco significativa y la infracción al deber funcional tenga o haya tenido como respuesta adecuada el reproche institucional y la sanción disciplinaria correspondientes" será procedente el principio de oportunidad. Sin embargo, y como concreción del principio de antijuridicidad material y sus principios derivados de subsidiariedad y fragmentariedad del derecho penal, consideramos que esta causal no debe predicarse únicamente de los delitos contra 
la administración pública o de la recta administración de justicia, sino en todos los delitos en los que, habiendo un injusto relevante para el derecho penal, hubiera otra solución sancionatoria del Estado, verbigracia, en los delitos económicos en los que hubiera una importante sanción de la Superintendencia de Industria y Comercio o los delitos ambientales, cuando haya una sanción del Ministerio del Medio Ambiente, o en los delitos contra la familia en los que ya exista una sanción por parte de las Comisarias de Familia, por mencionar algunos.

De esta forma se prioriza la competencia del derecho penal a los hechos más graves y se empoderan a otras autoridades para la búsqueda de una tutela judicial efectiva.

- Teniendo en cuenta que hay norma constitucional que autoriza a la víctima (acusador privado) y a ciertas entidades públicas presentar una acusación penal, proponemos que se haga una regulación que permita e incentive a la víctima a que aplique también el principio de oportunidad para que tutele sus derechos de una manera más eficiente dentro de la causa penal.

\subsection{Propuestas para mejorar la operatividad del principio de oportunidad}

Para que sea más fluida y recurrente la aplicación del principio de oportunidad pensamos que es adecuado lo siguiente:

- Se debería confiar al Fiscal General la formulación de unas directrices de aplicación del principio de oportunidad que deben acatar los fiscales de conocimiento, eliminar el límite de seis años de la causal 1 del artículo 324, para que los fiscales de conocimiento apliquen el principio de oportunidad directamente (como de manera tímida lo hizo la Resolución 2370 de 2016 de la Fiscalía) y fijar una competencia general para la aplicación del principio de oportunidad a los fiscales de conocimiento; pero, aclarando que hay causales que tienen una mayor trascendencia y, por esto, se le deben atribuir al Fiscal General o un delegado especial que designe. Es decir se debe dar una competencia general para las causales del principio de oportunidad a los fiscales de conocimiento, con exclusiones o reglas especiales de competencia de ciertas causales que solo puedan ser de conocimiento del Fiscal General o un delgado especial.

Para dar mayor control institucional la Fiscalía debe imponerles a los fiscales de conocimiento el deber presentar un informe trimestral o semestral al Fiscal Delegado ante el Tribunal y al Ministerio Público sobre la aplicación del principio de oportunidad. Suspender el término de prescripción al momento de iniciar el trámite y el procedimiento a prueba en el principio de oportunidad para que los fiscales no tengan inseguridad de que por tramitar un principio de oportunidad van a incurrir en prescripciones penales y no desincentiven la práctica de este proceder. 
- El parágrafo $1 .^{\circ}$ del artículo 324 excluye del principio de oportunidad a cabecillas, jefes o determinadores de organizaciones criminales de la aplicación de las causales 4 y 5. Estas causales dicen: "4. Cuando el imputado o acusado, hasta antes de iniciarse la audiencia de juzgamiento, colabore eficazmente para evitar que el delito continúe ejecutándose, o que se realicen otros, o cuando suministre información eficaz para la desarticulación de bandas de delincuencia organizada" y "5. Cuando el imputado o acusado, hasta antes de iniciarse la audiencia de juzgamiento, se compromete a servir como testigo de cargo contra los demás procesados, bajo inmunidad total o parcial. En este evento los efectos de la aplicación del principio de oportunidad quedarán en suspenso respecto del procesado testigo hasta cuando cumpla con el compromiso de declarar. Si concluida la audiencia de juzgamiento no lo hubiere hecho, se revocará el beneficio".

Concebimos adecuado excluir a estas personas del beneficio del principio de oportunidad al considerar que la calidad de líderes o determinadores de delincuencia organizada hace necesaria la imposición de una pena.

Sin embargo, en caso de que estos criminales se encuentren cumpliendo una pena de prisión y se llegase a condenar a los mismos, la acumulación de la pena ante el juez de ejecución de penas implicaría un aumento insignificante en las penas que están cumpliendo.

Por lo anterior proponemos permitir aplicar las causales 4 y 5 del principio de oportunidad a líderes o determinadores de organizaciones criminales que se encuentren cumpliendo pena y que la futura acumulación de pena no implique un gran aumento en la privación de la libertad que están cumpliendo, pues pensamos que aunque estos delincuentes merecen la imposición de una medida restrictiva de la libertad, el aumento en la privación de la libertad que se les irrogue puede resultar despreciable respecto de la cooperación que puedan prestar para desmantelar bandas criminales.

- Crear una condición abierta e indeterminada que se le imponga al procesado para que cumpla en el período de suspensión de la persecución penal, pues en casos particulares puede haber condiciones más útiles político-criminalmente que las que están previstas en el artículo 326 del cPP.

- En vista de que el principio de oportunidad se debe aplicar en la mayor medida posible y busca imponer medidas más útiles político-criminalmente, proponemos que se permita adelantar o tramitar el principio de oportunidad hasta antes de que se dé la lectura de fallo de primera o segunda instancia con el que se condenará a los acusados.

- Crear causales de principio de oportunidad para que en ciertos casos se renuncie, suspenda o interrumpa la acción penal en caso de entregar voluntariamente o facilitar sus bienes para que se realice la extinción de dominio, aclarando que esto solo versará respecto de ciertos delitos. 
- Teniendo en cuenta la facultad de las víctimas de presentar acusación penal y la propuesta antes anunciada de crear una institucionalidad para la aplicación del principio de oportunidad por parte de la víctima, proponemos adicionar a las condiciones del período de prueba sanciones como multas en favor del Estado y de las víctimas y demás afectados (punitive damages) que generen una efectiva prevención especial en los delincuentes y hagan atractivo para las víctimas la aplicación del principio de oportunidad.

- Conceder renuncia a la persecución penal a personas que hubieran sido reclutadas forzosamente desde niños, por los distintos grupos criminales, afectados sicológica y siquiátricamente por el ambiente de violencia o que se hubieran formado en condiciones de maltrato, descuido familiar y resentimiento social para darles un tratamiento más humano y terapéutico e incentivar de una manera más eficaz la función de prevención especial que también busca el derecho penal.

\section{ANEXOS}

Con el fin de entender el panorama práctico referente a la aplicación del principio de oportunidad, una vez clara la reglamentación interna de la Fiscalía General de la Nación, se solicitaron al Director Nacional del Sistema Penal Acusatorio, mediante derecho de petición, estadísticas sobre el número de solicitudes que se han tramitado de Principio de Oportunidad a Nivel Central y Seccional, las causales por las cuales se solicitaron, la modalidad y el número de solicitudes aprobadas, en un marco temporal de los últimos cinco años.

Como respuesta al derecho de petición, se obtuvo el 22 de agosto de 2016 información que data del primero de agosto de 2011 al 12 de agosto de 2016 . En primera medida, se establece que la cantidad de solicitudes para aplicación del principio de oportunidad ascendió a 9.858 . 


\begin{tabular}{|c|c|}
\hline \multicolumn{2}{|c|}{ Principio de oportunidad 2011-2016 } \\
\hline Seccionales & Cantidad \\
\hline Bogotá & 3.260 \\
\hline Ibagué & 780 \\
\hline Cundinamarca & 726 \\
\hline Tunja & 554 \\
\hline Bucaramanga & 488 \\
\hline Pereira & 482 \\
\hline Cali & 451 \\
\hline Armenia & 416 \\
\hline Medellín & 415 \\
\hline Neiva & 305 \\
\hline Villavicencio & 235 \\
\hline Popayán & 225 \\
\hline Antioquia & 201 \\
\hline Nivel central & 199 \\
\hline Pasto & 180 \\
\hline San Gil & 159 \\
\hline Cúcuta & 127 \\
\hline Riohacha & 124 \\
\hline Arauca & 91 \\
\hline Cartagena & 78 \\
\hline Santa Rosa de Viterbo & 75 \\
\hline Manizales & 74 \\
\hline Buga & 57 \\
\hline Florencia & 53 \\
\hline Barranquilla & 43 \\
\hline Quibdó & 19 \\
\hline Montería & 11 \\
\hline Valledupar & 11 \\
\hline Mocoa & 10 \\
\hline Santa Marta & 7 \\
\hline Sincelejo & 2 \\
\hline Total general & 9.858 \\
\hline
\end{tabular}




\begin{tabular}{|c|c|c|c|c|c|c|c|c|c|c|c|c|c|c|c|c|c|c|c|}
\hline & 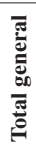 & ळे & $\underset{\sim}{\stackrel{N}{ }}$ & $\bar{\sigma}$ & $\stackrel{0}{7}$ & q & ָે & $\begin{array}{c}\infty \\
\stackrel{\infty}{\alpha}\end{array}$ & in & $\vec{r}$ & I & 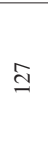 & ¿̊ & in & $\stackrel{\infty}{\triangleright}$ & $\stackrel{ \pm}{\sim}$ & $\stackrel{\Xi}{\forall}$ & 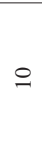 & $=$ \\
\hline & 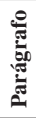 & & & & & & in & $N$ & & & & & & & in & & & & \\
\hline & $\begin{array}{l}\stackrel{\infty}{6} \\
\stackrel{0}{\Xi}\end{array}$ & & & & & & & - & & 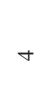 & & 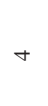 & - & - & & & & & \\
\hline & 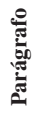 & & & & & & & & & & & & & & - & & & & \\
\hline & $=$ & & & & & & & & & & - & & & & & & & & \\
\hline & 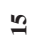 & & & & - & & & - & & - & - & & N & & & & & & \\
\hline & $\Xi$ & & $m$ & & - & & \pm & $\sim$ & & in & 0 & & in & - & & - & in & & \\
\hline & 2 & - & ల & $n$ & in & $m$ & $\stackrel{\partial}{\exists}$ & 2 & $\stackrel{\sim}{i}$ & d & $r$ & $\hat{a}$ & $=$ & - & $\underline{n}$ & $=$ & $\stackrel{\circ}{\simeq}$ & & \\
\hline & $\simeq$ & $m$ & $\stackrel{m}{\infty}$ & ナ & \pm & 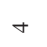 & "ే & in & - & $\stackrel{0}{0}$ & లి & $\simeq$ & $\stackrel{t}{\Xi}$ & $m$ & 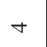 & in & $m$ & & \\
\hline స్ & $=$ & & & & $\simeq$ & & - & - & & - & & - & in & & - & & & & \\
\hline & $\varrho$ & & - & & & & & $m$ & & & & & & $\alpha$ & t & & $N$ & & \\
\hline & $a$ & - & $m$ & - & 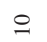 & & \pm & 0 & - & r & & - & in & & r & in & $a$ & - & - \\
\hline & $\infty$ & & & & & & 0 & & & - & & & & & & & & & \\
\hline & r & $\approx$ & I & 인 & 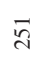 & $=$ & $\underset{\vec{i}}{\stackrel{ \pm}{\vec{i}}}$ & 2 & a & $\stackrel{\infty}{\sim}$ & $\ddot{n}$ & 9 & $\underset{ల}{0}$ & $r$ & $\vec{n}$ & $\stackrel{\infty}{\mathscr{1}}$ & : & $r$ & \\
\hline & 0 & $N$ & 0 & $r$ & & & 2 & $N$ & 0 & $\stackrel{0}{0}$ & & - & $\simeq$ & $m$ & $m$ & $\simeq$ & $N$ & & \\
\hline & in & Ұ & $\simeq$ & & ల & + & in & $\stackrel{\infty}{\longrightarrow}$ & $a$ & $\ddot{d}$ & & $N$ & $=$ & r & $\cong$ & r & $\cong$ & $N$ & \\
\hline & $\sigma$ & t & in & $m$ & - & $m$ & $\stackrel{0}{0}$ & in & - & $=$ & - & t & $a$ & $N$ & $=$ & & r & & - \\
\hline & $N$ & & & & & & & & & & & & & & & & & & \\
\hline & - & $a$ & $\stackrel{\sim}{\sim}$ & $=$ & $\bar{m}$ & $\stackrel{\infty}{\longrightarrow}$ & $\approx$ & in & $a$ & $\tilde{\infty}$ & $m$ & $\widehat{\sigma}$ & $\stackrel{\infty}{\longrightarrow}$ & a & $\stackrel{\sim}{\sim}$ & $a$ & $\stackrel{\infty}{\sim}$ & & $a$ \\
\hline & 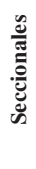 & 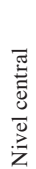 & 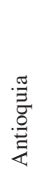 & 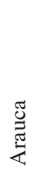 & 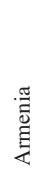 & 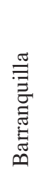 & 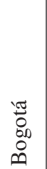 & 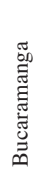 & 萢 & 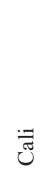 & 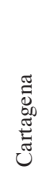 & 莺 & 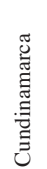 & $\begin{array}{l}\frac{\pi}{0} \\
\frac{0}{0} \\
\frac{0}{I}\end{array}$ & 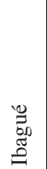 & 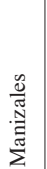 & $\begin{array}{l}\frac{\Xi}{\overline{0}} \\
\frac{0}{\Sigma}\end{array}$ & 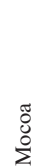 & 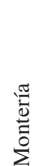 \\
\hline
\end{tabular}




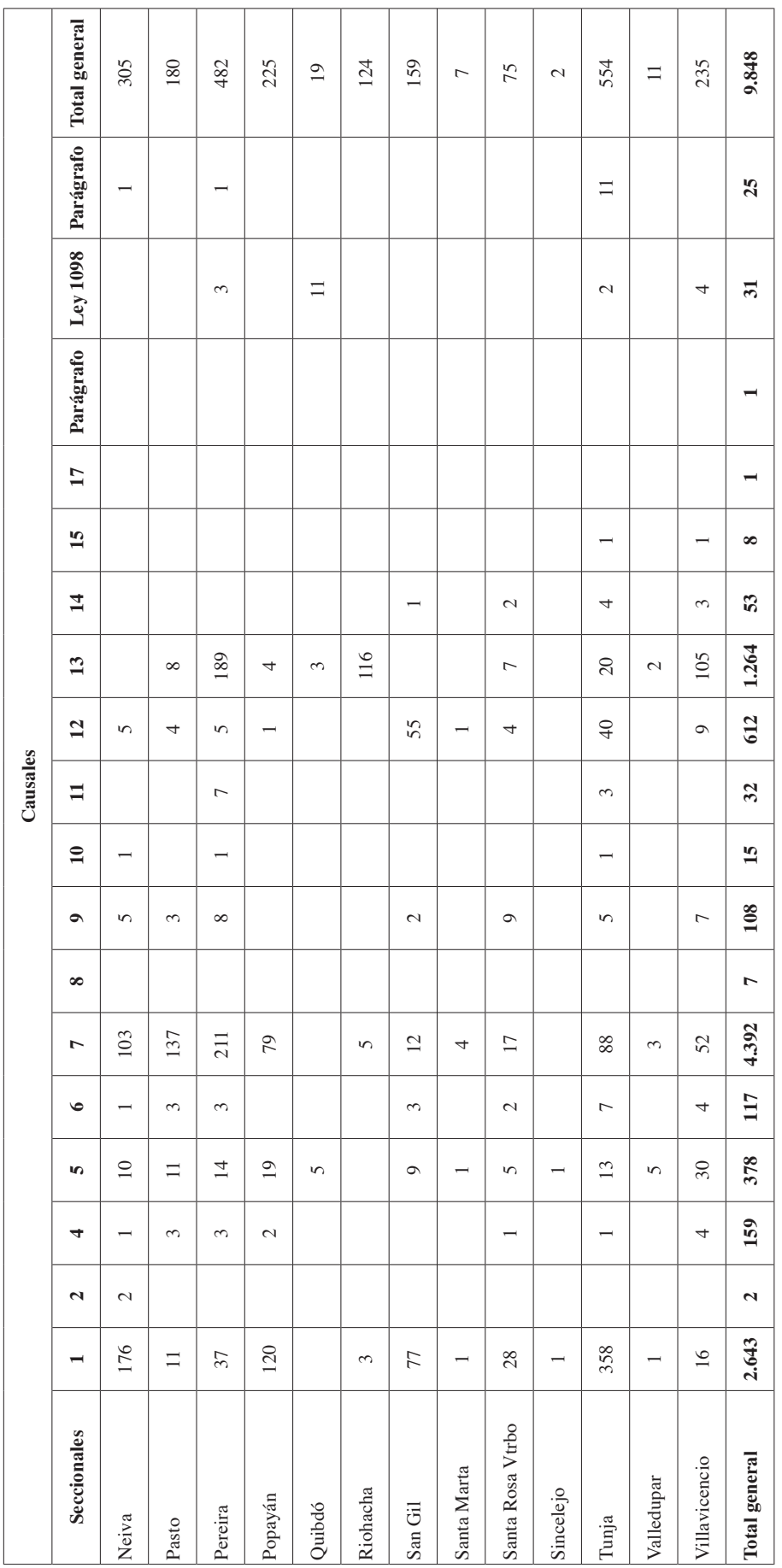


A continuación se presenta la tabla consolidada de las modalidades en las que se aplicó el principio las abstenciones, los desistimientos, las negativas y el número de solicitudes que están pendientes por resolver. Cabe resaltar que estos datos se refieren a las decisiones expedidas por el Fiscal General de la Nación o su delegado especial.

\begin{tabular}{|c|c|}
\hline $\begin{array}{c}\text { Modalidades aplicación principio de oportunidad periodo comprendido } \\
\text { desde el 1 de agosto de 2011 al 12 de agosto de 2016 } \\
\text { (decisiones del FGN o su delegado especial) }\end{array}$ \\
\hline Modalidad & Cantidad \\
\hline Interrupción & 75 \\
\hline Suspensión & 3.341 \\
\hline Renuncia & 3.539 \\
\hline Prórroga interrupción & 16 \\
\hline Prórroga suspensión & 42 \\
\hline Abstención & 603 \\
\hline Desistimiento & 15 \\
\hline Negativa & 1.834 \\
\hline Pendiente información de decisión & 383 \\
\hline Total & $\mathbf{9 . 8 4 8}$ \\
\hline
\end{tabular}

\section{Decisiones aprobadas $=\mathbf{2 . 6 2 4}$}

\section{BIBLIOGRAFÍA}

Aristizábal GonZÁlez, CARolina (2005). Alcance del principio de oportunidad en la nueva legislación procesal penal colombiana. Bogotá: Pontificia Universidad Javeriana.

Armenta Deu, Teresa (2009). Lecciones de derecho procesal penal. Madrid: Marcial Pons.

Barbosa Castillo, Gerardo (2005). "Principio de legalidad y proceso penal", en Revista Derecho Penal y Criminología, Vol. 26, n. ${ }^{\circ} 78$, enero-junio de 2005. Bogotá: Universidad Externado de Colombia, 2005, pp. 109-124. 
Carocca Pérez, Alex (2009). Manual el nuevo sistema procesal penal chileno. Santiago: Thomson Reuters.

Colquitt, Joseph (feb., 2001). "Ad hoc plea Bargaining”, en Tulane Law Review, n. ${ }^{\circ} 75$. Nueva Orleans: Universidad de Tulane.

Daza GonzÁlez, Alfonso (2011). La discrecionalidad en el ejercicio de la acción penal frente a los fines del proceso penal en el Estado Social de Derecho. Bogotá: Universidad Libre.

Díez-Picazo, Luis María (2000). El poder de acusar. Ministerio fiscal y constitucionalismo. Barcelona: Ariel Derecho.

Forero Ramírez, JuAn CARlos (2013). Aproximación al Estudio del Principio de Oportunidad. Bogotá: Editorial Ibáñez.

Gómez Pavajeau, Carlos Arturo (2016). "En defensa y promoción del principio de oportunidad", en Balance crítico del sistema acusatorio a los diez años de su vigencia. Bogotá: Defensoría del Pueblo.

Gómez PaVAjeau, Carlos Arturo (2016). La oportunidad como principio complementario del proceso penal. Bogotá: Editorial Nueva Jurídica.

Granados Peña, Jaime (1996). El sistema acusatorio en el derecho comparado y la nueva Fiscalía General en Colombia. Bogotá: Editorial Ibáñez.

Guerrero, ÓSCAR Julián (2013). Fundamentos teórico constitucionales del nuevo proceso penal. Bogotá: Ediciones Nueva Jurídica.

GutiÉRREZ BELTRÁn, ANDRÉS (2007). El bloque de constitucionalidad, conceptos y fundamentos. Bogotá: Universidad Externado de Colombia.

Mestre Ordoñez, José Fernando (2011). La discrecionalidad para acusar. Bogotá: Editorial Ibáñez.

Pendleton, Howard (Jun., 1929). "Criminal Prosecution in England. I. Police Prosecutions", en Columbia Law Review, Vol. 29, n. 6.

Perdomo Torres, Jorge Fernando (2005). Los principios de le galidad y oportunidad. Fundamentos constitucionales y teórico penales, y su regulación en el derecho procesal penal colombiano. Bogotá: Universidad Externado de Colombia.

Roxin, Claus (2000). Derecho Procesal Penal. Buenos Aires: Editores del Puerto. 
Salzburg, Stephen A. y Capra, Daniel J. (2010). American Criminal Procedure. Estados Unidos: West.

Urbano Martínez, José JoAquín (2003). “El principio de oportunidad en el proyecto de Código de Procedimiento Penal -Estado actual-", en Revista Derecho Penal y Criminología, Vol. 24, n. ${ }^{\circ}$ 74. Bogotá: Universidad Externado de Colombia, pp. 195-208.

Urbano Martínez, José JoAquín (2006). “Los fines constitucionales del proceso penal como parámetros de control del principio de oportunidad", en Revista Derecho Penal y Criminología, Vol. 27, n. ${ }^{\circ}$ 80, enero-junio de 2006. Bogotá: Universidad Externado de Colombia, pp. 121 a 125.

Villanueva Meza, Javier Antonio (2005). El principio de oportunidad. Bogotá: Leyer.

Villar Borda, Luis (2007). "El Estado de Derecho y Estado Social de Derecho", en Revista Derecho del Estado, n. ${ }^{\circ} 20$, diciembre de 2007. Bogotá: Universidad Externado de Colombia, pp. 73-96.

Younes Moreno, Diego (2014). Derecho Constitucional Colombiano, 13. a ed. Bogotá: Legis. 